\title{
Article \\ Renal Tubular Epithelial TRPA1 Acts as An Oxidative Stress Sensor to Mediate Ischemia-Reperfusion-Induced Kidney Injury through MAPKs/NF- $\mathrm{B}$ Signaling
}

\author{
Chung-Kuan $\mathrm{Wu}^{1,2}{ }^{\mathbb{D}}$, Chia-Lin $\mathrm{Wu}{ }^{3,4} \mathbf{D}^{\mathbb{D}}$, Tzong-Shyuan Lee ${ }^{5} \mathbb{D}$, Yu Ru Kou ${ }^{6, *(D)}$ and \\ Der-Cherng Tarng 6,7,8,9,10,*(D)
}

1 Division of Nephrology, Department of Internal Medicine, Shin-Kong Wu Ho-Su Memorial Hospital, Taipei 111, Taiwan; chungkuan.wu@gmail.com

2 School of Medicine, Fu-Jen Catholic University, New Taipei 242, Taiwan

3 Division of Nephrology, Department of Internal Medicine, Changhua Christian Hospital, Changhua 500, Taiwan; 143843@cch.org.tw

4 School of Medicine, Chung-Shan Medical University, Taichung 402, Taiwan

5 Department of Physiology, College of Medicine, National Taiwan University, Taipei 106, Taiwan; ntutslee@ntu.edu.tw

6 Department of Institute of Physiology, School of Medicine, National Yang-Ming University, Taipei 112, Taiwan

7 Department of Biological Science and Technology, National Chiao Tung University, Hsinchu 300, Taiwan

8 Center for Intelligent Drug Systems and Smart Bio-devices (IDS2B), Hsinchu 300, Taiwan

9 Division of Nephrology, Department of Medicine, Taipei Veterans General Hospital, Taipei 112, Taiwan

10 Institute of Clinical Medicine, National Yang-Ming University, Taipei 112, Taiwan

check for

updates

Citation: Wu, C.-K.; Wu, C.-L.; Lee, T.-S.; Kou, Y.R.; Tarng, D.-C. Renal Tubular Epithelial TRPA1 Acts as An Oxidative Stress Sensor to Mediate Ischemia-Reperfusion-Induced Kidney Injury through MAPKs / NF-кB Signaling. Int. J. Mol. Sci. 2021, 22, 2309. https://doi.org/10.3390/ ijms22052309

Academic Editor: Viktorie Vlachova

Received: 30 January 2021

Accepted: 23 February 2021

Published: 25 February 2021

Publisher's Note: MDPI stays neutral with regard to jurisdictional claims in published maps and institutional affiliations.

Copyright: (c) 2021 by the authors. Licensee MDPI, Basel, Switzerland. This article is an open access article distributed under the terms and conditions of the Creative Commons Attribution (CC BY) license (https:// creativecommons.org/licenses/by/ $4.0 /)$.

* Correspondence: yrkou@ym.edu.tw (Y.R.K.); dctarng@vghtpe.gov.tw (D.-C.T.)

\begin{abstract}
Oxidative stress and inflammation play important roles in the pathophysiology of acute kidney injury (AKI). Transient receptor potential ankyrin 1 (TRPA1) is a Ca2+-permeable ion channel that is sensitive to reactive oxygen species (ROS). The role of TRPA1 in AKI remains unclear. In this study, we used human and animal studies to assess the role of renal TRPA1 in AKI and to explore the regulatory mechanism of renal TRPA1 in inflammation via in vitro experiments. TRPA1 expression increased in the renal tubular epithelia of patients with AKI. The severity of tubular injury correlated well with tubular TRPA1 or 8-hydroxy-2'-deoxyguanosine expression. In an animal model, renal ischemia-reperfusion injury (IR) increased tubular TRPA1 expression in wild-type (WT) mice. Trpa1 ${ }^{-/-}$mice displayed less IR-induced tubular injury, oxidative stress, inflammation, and dysfunction in kidneys compared with WT mice. In the in vitro model, TRPA1 expression increased in renal tubular cells under hypoxia-reoxygenation injury $(\mathrm{H} / \mathrm{R})$ conditions. We demonstrated that $\mathrm{H} / \mathrm{R}$ evoked a ROS-dependent TRPA1 activation, which elevated intracellular $\mathrm{Ca}^{2+}$ level, increased NADPH oxidase activity, activated MAPK/NF- $\mathrm{kB}$ signaling, and increased IL-8. Renal tubular TRPA1 may serve as an oxidative stress sensor and a crucial regulator in the activation of signaling pathways and promote the subsequent transcriptional regulation of IL- 8 . These actions might be evident in mice with IR or patients with AKI.
\end{abstract}

Keywords: acute kidney injury; TRPA1; oxidative stress; inflammation; renal tubule cells

\section{Introduction}

Renal ischemia-reperfusion injury (IR) is among the most common causes of renal dysfunction and acute kidney injury (AKI) [1,2]. Oxidative stress and inflammation play important roles in the pathophysiology of IR-induced AKI [1-6]. During the reperfusion phase of IR, excess generation of reactive oxygen species (ROS) occurs, leading to the increase in oxidative stress in renal tissues [2-5]. These ROS then initiate a complex mechanism that involves various types of cells and inflammatory mediators leading to AKI $[1,2,4,6]$. For example, renal tubular epithelial cells are vulnerable to oxidative stress 
and their injury is a key feature of the initiation phase of IR-induced AKI [7-9]. IR may also increase intracellular ROS to aggregate injury through the activation of NADPH oxidase [9-11], which is a primary enzyme system that generates ROS in mammalian cells [12]. IR induces inflammatory mediators such as interleukin-8 (IL-8), monocyte chemoattractant protein 1 (MCP-1), and macrophage inflammatory protein 2 (MIP-2), which are important chemokines that initiate and amplify renal inflammation [6,13-15]. These inflammatory mediators may be produced by signaling mechanisms [1], such as the redox-sensitive mitogen-activated protein kinases (MAPKs)/nuclear factor- $\mathrm{kB}$ (NF- $\mathrm{kB}$ ) pathway $[5,11,16-18]$. However, the way by which renal tubular epithelial cells can sense IR-induced oxidative stress and translate these cellular events remains unclear.

Transient receptor potential ankyrin 1 (TRPA1), which is a type of nonselective transmembrane cation channel, is involved in $\mathrm{Ca}^{2+}$ permeability $[19,20]$. Neuronal TRPA1 acts as a sensor of toxic signals and molecular integrator of cellular stress, including ROS [20,21]. Recent studies have demonstrated that TRPA1 is expressed in various types of non-neuronal cells, including renal epithelial tubular cells [22,23]. Promoting inflammation is among the major functions of TRPA1 in non-neuronal cells [24]. For example, the stimulation of lung epithelial cells by cigarette smoke, which is a major oxidant, increases the TRPA1-mediated production of IL-8 [25,26]. In mice, epithelial TRPA mediates lung inflammation due to cigarette smoke $[25,26]$. Nevertheless, whether TRPA1 plays a role in the IR-induced inflammation and injury in the kidney remains unclear, because recent studies demonstrated that TRPA1 may protect against sepsis-induced or Ang II-induced and IR injury by modulating mitochondrial biogenesis and mitophagy or by inhibiting macrophage-mediated inflammation [27-29].

The aims of the study are as follows: first, to assess the correlation between the expression of renal tubular TRPA1 or 8-hydroxy-2'-deoxyguanosine (8-OHdG, a biomarker of oxidative stress) and the severity of renal tubular injury in patients with acute tubular necrosis (ATN); second, to compare renal oxidative stress, inflammation, dysfunction, and injury induced by renal IR between wild-type (WT) and trpa1 ${ }^{-/-}$mice; and finally, to investigate how renal tubular TRPA1 acts as a crucial regulator in the activation of signaling pathways and promotes IL-8 induction in renal tubular epithelial (HK-2) cells in response to hypoxia-reoxygenation injury $(\mathrm{H} / \mathrm{R})$, through an in vitro model that mimics in vivo IR [30].

\section{Results}

\subsection{Patients with ATN and AKI Display Increased Expression of Renal Tubular TRPA1} and $8-O H d G$

Immunohistochemical analyses showed stronger positive staining for TRPA1 or 8OHdG in the tubular epithelia of renal sections from a patient with ATN than in that from a normal control subject (Figure 1A). Analysis of quantitative staining values revealed that the expression of renal tubular TRPA1 or 8-OHdG in the ATN group was significantly higher than in the control group (Figure 1B). Renal tubular injury scores were then evaluated by using renal sections stained via periodic acid-Schiff (PAS). Tubular injury score was highly correlated with the expression of renal tubular TRPA1 (Figure $1 \mathrm{C} ; r=0.89$ ) or 8-OHdG (Figure 1D; $r=0.94$ ).

\subsection{IR Increases the Expression of TRPA1 in Renal Tubular Epithelia and Renal Tissues in WT Mice, but Not in trpa1 ${ }^{-/}$Mice}

Immunohistochemical analyses of renal sections obtained from WT mice subjected to the sham treatment revealed that their tubular epithelia displayed stronger positive staining for TRPA1 than the tubular epithelia from trpa1 ${ }^{-/-}$mice subjected to the sham treatment (Figure 2A). Additionally, the positive staining for TRPA1 in tubular epithelia from WT mice with IR was much stronger than that from WT mice subjected to the sham treatment (Figure 2A). By contrast, the positive staining for TRPA1 in tubular epithelia from trpa1 $1^{-/-}$mice with IR was only mildly increased compared with that from trpa1 ${ }^{-/-}$ 
mice subjected to the sham treatment (Figure 2A). Western blot analyses using renal tissues revealed that IR significantly increased the protein expression of TRPA1 in WT mice but not in $\operatorname{trpa}^{-/-}$mice (Figure 2). Immunohistochemical and western blotting analyses of renal tissues obtained from the trpa1 $1^{-/-}$mice displayed mild TRPA1 protein expression because the trpa1 ${ }^{-/-}$mice were functional knockout mice with the S5/S6 transmembrane domains of targeted gene deleted.
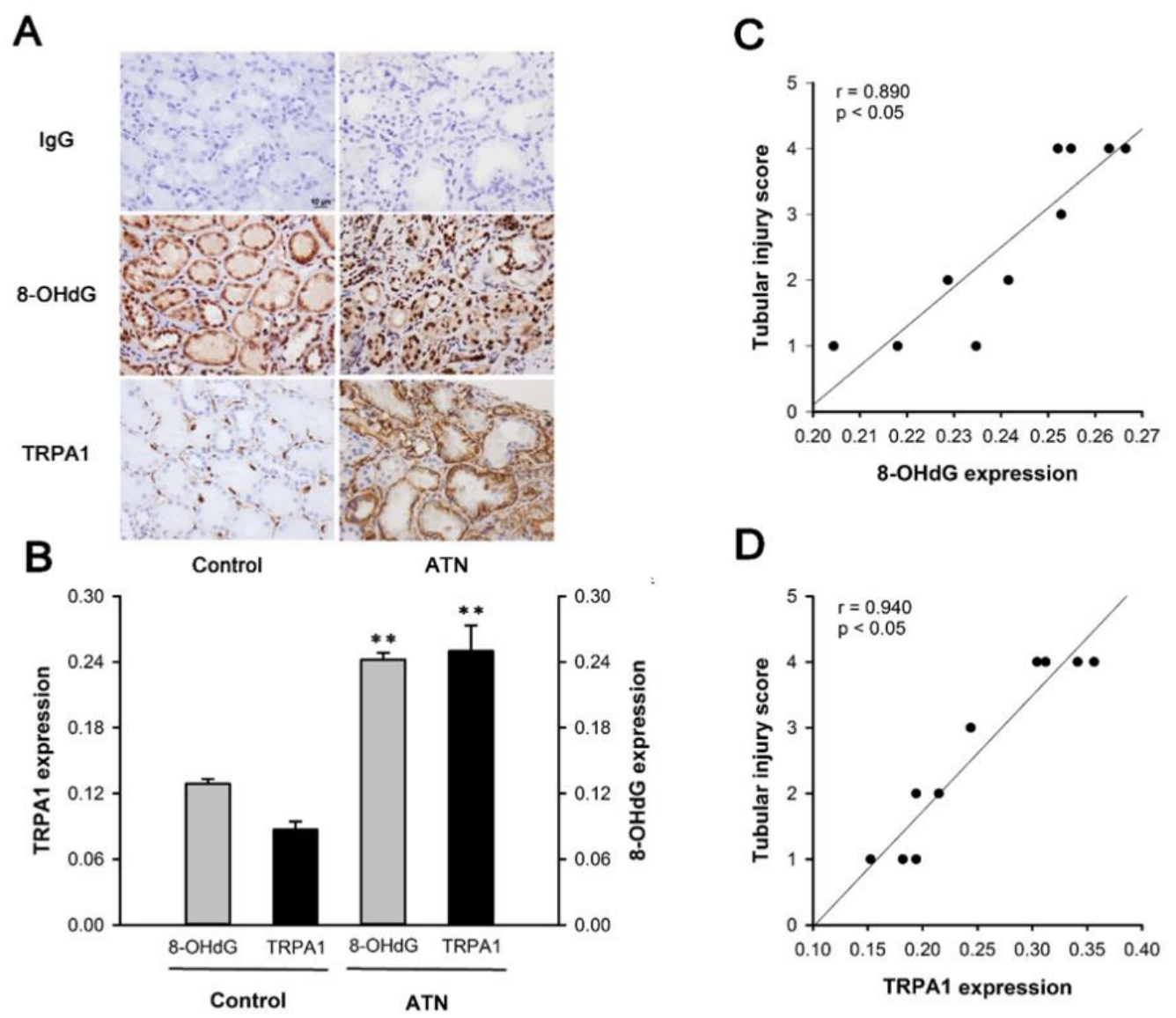

Figure 1. Patients with acute tubular necrosis (ATN) and acute renal injury display increased expression of renal tubular transient receptor potential ankyrin 1 (TRPA1) and 8-hydroxy-2'-deoxyguanosine (8-OHdG), a biomarker of oxidative stress. (A) Representative images showing immunostaining with an antibody against TRPA1 or 8-OHdG. Renal sections were obtained from normal control subjects and patients with ATN. The specificity of the immunostaining was confirmed by using an IgG-negative control. The magnification of each panel was $400 \times$. (B) Quantification of the expression levels of renal tubular TRPA1 and 8-OHdG in the renal sections with immunostaining. Data in each group are the mean \pm SEM from 10 patients. ${ }^{* *} p<0.01$ versus the control group. (C,D) Pearson correlation analyses of expression of renal tubular TRPA1 or 8-OHdG with tubular injury score in patients with ATN $(n=10)$; r represents the correlation coefficient. Tubular injury score was calculated according to the percentage of injured area of tubular cross sections. The scoring system is described in the Methods section. 
A

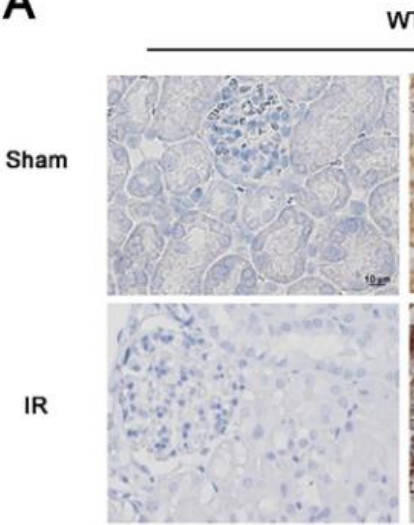

$\lg G$
WT

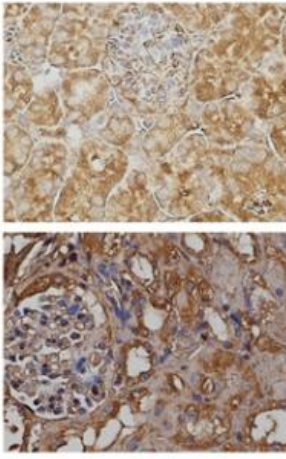

TRPA1

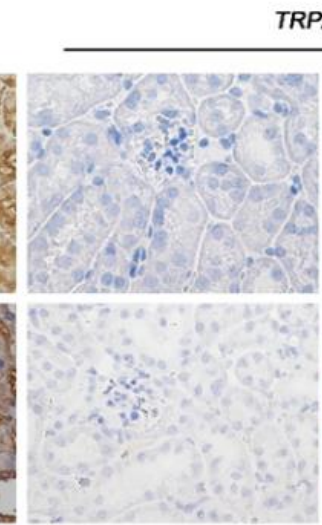

$\lg G$
TRPA

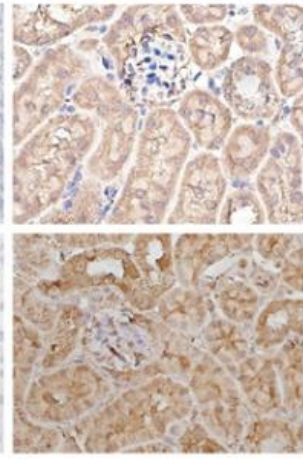

TRPA1

B
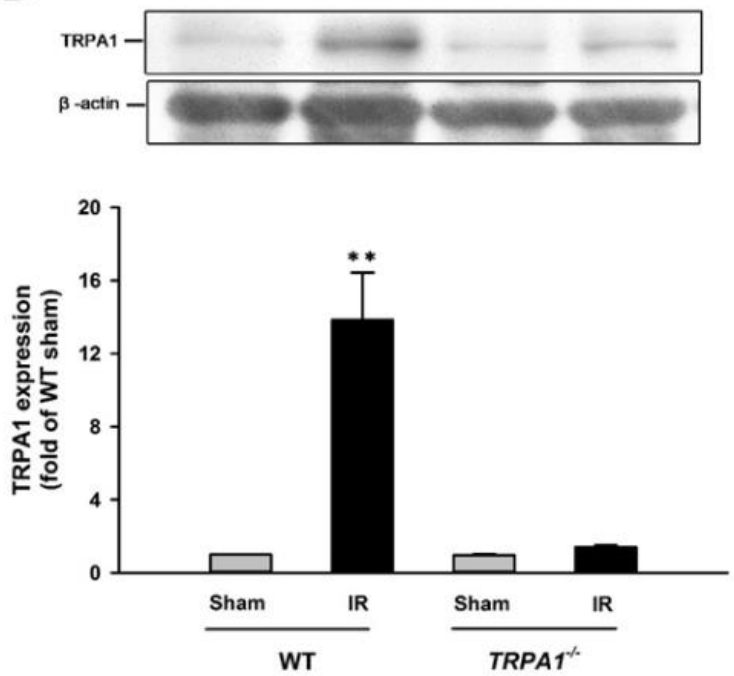

Figure 2. IR increases TRPA1 expression in renal tubular epithelia and renal tissues in wild type (WT) mice, but not in trpa1 ${ }^{-/-}$mice. (A) Representative images showing immunostaining with a TRPA1 antibody. Renal sections were obtained from two genotypes of mice subjected to two different treatments. The specificity of the immunostaining was confirmed using an IgG-negative control. The magnification of each panel was $400 \times$. Note that the expression of tubular TRPA1 was increased by ischemia reperfusion (IR) only in WT mice. (B) Protein levels of TRPA1 in renal tissues obtained from the two genotypes of mice subjected to two different treatments. Protein expression was analyzed by Western blot. Immunohistochemical and Western blot analyses of renal tissues obtained from the trpa $1^{-/-}$mice displayed mild TRPA1 protein expression because they were functional knockout mice with the S5/S6 transmembrane domains of targeted gene deleted. Data in each group are mean \pm SEM from 6 mice. ** $p<0.01$ versus sham treatment.

\subsection{Renal Tubular Injury Induced by IR Is Lessened in trpa1 ${ }^{-/-}$Mice}

Renal sections from WT mice with IR showed severe tubular injury lesions, manifested by loss of brush border, flattening, and loss of tubular epithelium and nuclear fragmentation. The extent of IR-induced changes was less in the trpa1-/- mice (Figure 3A). Further analyses revealed that IR increased the tubular injury scores of both genotypes of mice relative to the scores of mice subjected to the sham treatment (Figure 3B). The trpa1 ${ }^{-/-}$mice with IR had significantly lower tubular injury score than the WT mice with IR (Figure 3B). 
A

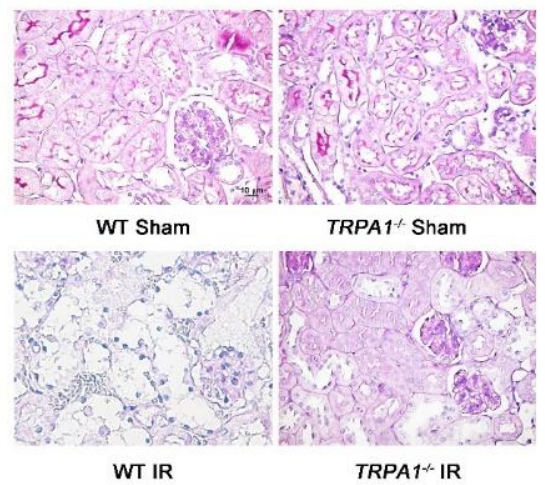

B

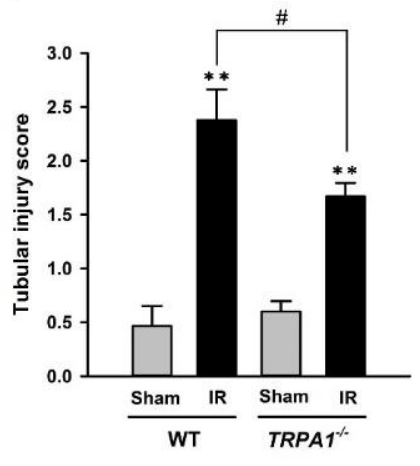

Figure 3. Renal tubular injury induced by IR is less in trpa1 $1^{-/-}$mice. (A) Representative images of periodic acid-Schiff (PAS) staining in renal sections obtained from the two genotypes of mice subjected to two different treatments. The magnification of each panel was $400 \times$. (B) Tubular injury score was calculated according to the percentage of injured area of tubular cross sections. The scores system is described in the methods. Data in each group are mean \pm SEM from 6 mice. ${ }^{* *} p<0.01$ versus the sham group in each genotype; ${ }^{\#} p<0.05$ versus the IR group of WT mice.

\subsection{I/R-Induced Increase in Biomarker Levels of Renal Oxidative Stress, Inflammation,}

Dysfunction, and Injury Is Alleviated in Trpa1 ${ }^{-/-}$Mice

We compared the biomarker levels of renal oxidative stress (Figure 4A; CL-detectable superoxide anion in renal tissues), inflammation (Figure 4B,C; MCP-1 and MIP-2 in renal tissues), dysfunction (Figure 4D,E; urea nitrogen and creatinine in the blood), and kidney injury (Figure 4F; NGAL, a biomarker of kidney injury, in renal tissues) among the four study groups. IR significantly increased the levels of all biomarkers measured in both genotypes of mice compared with the levels in the mice subjected to the sham treatment (Figure 4). The levels of these biomarkers in trpa1 ${ }^{-/-}$mice with IR were significantly lower than those in WT mice with IR (Figure 4).

A

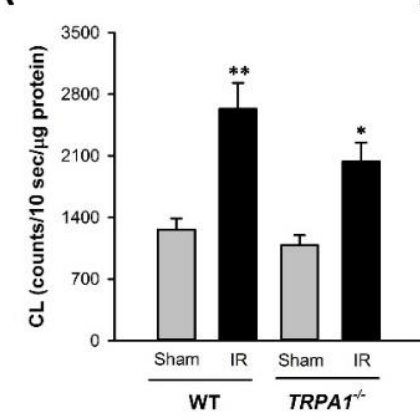

D

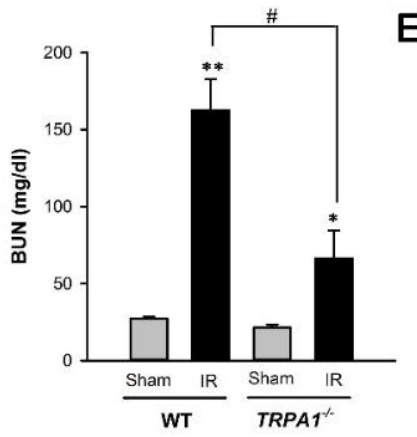

B

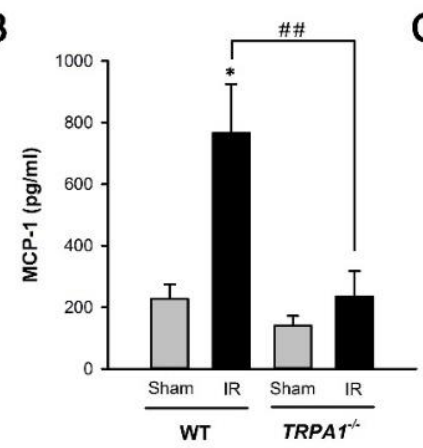

E

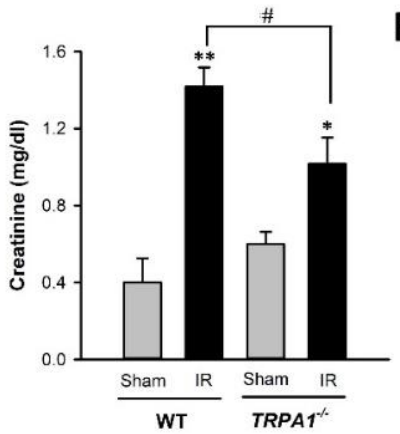

C

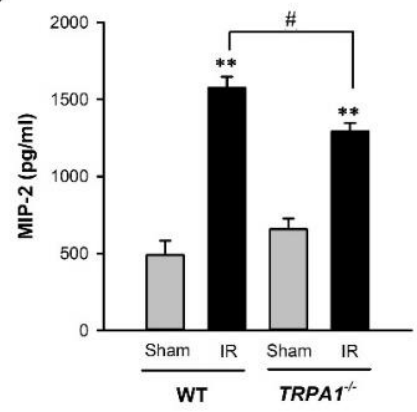

$\mathbf{F}$

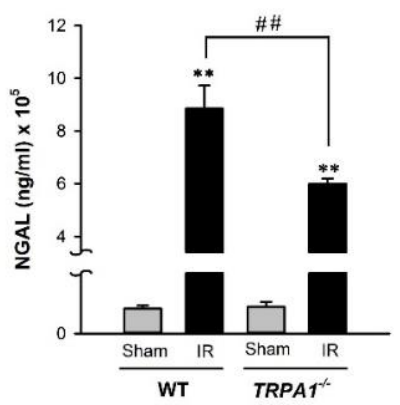

Figure 4. Increases in biomarker levels of renal oxidative stress, inflammation, dysfunction, and injury induced by IR are all alleviated in trpa1 ${ }^{-/-}$mice. (A) Quantitative data of CL counts using 
renal tissues for analyses. Data are presented as CL counts per $10 \mathrm{sec} / \mu \mathrm{g}$ protein from renal tissue lysates. (B) MCP-1, monocyte chemoattractant protein 1. (C) MIP-2, macrophage inflammatory protein 2, (D) BUN, blood urea nitrogen, (E) blood level of creatinine, (F) tissue levels of neutrophil gelatinase-associated lipocalin (NGAL), which is a biomarker of AKI, were analyzed by ELISA. Data in each group are mean \pm SEM from 6 independent experiments. ${ }^{*} p<0.05$ versus the sham group in each genotype; ${ }^{* *} p<0.01$ versus the sham group in each genotype; ${ }^{*} p<0.05$ versus the IR group of WT mice; ${ }^{\# \#} p<0.01$ versus the IR group of WT mice.

\subsection{H/R Increases the TRPA1 Expression in HK-2 Cells}

The exposure of $\mathrm{HK}-2$ cells to various $\mathrm{O}_{2}$ concentrations $(10 \%, 5 \%$ and $2.5 \%)$ for $6 \mathrm{~h}$ and subsequent reoxygenation for $4 \mathrm{~h}$ caused concentration-dependent increase in TRPA1 protein expression (Figure 5A). Moreover, the exposure of $\mathrm{HK}-2$ cells to $2.5 \% \mathrm{O}_{2}$ for various durations $(1,3$, and $6 \mathrm{~h}$ ), followed by reoxygenation for $4 \mathrm{~h}$, caused time-dependent increase in TRPA1 expression (Figure 5B). Exposure of HK-2 cells to $2.5 \% \mathrm{O}_{2}$ for $6 \mathrm{~h}$, followed by reoxygenation for $4 \mathrm{~h}$, was then selected as the standard $H / R$ conditions for the study of IL-8 induction and the signaling pathway involved.

A

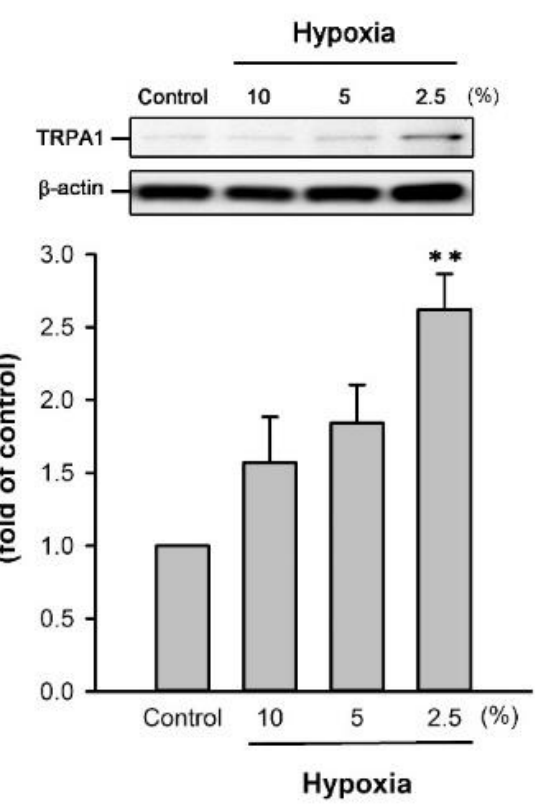

B

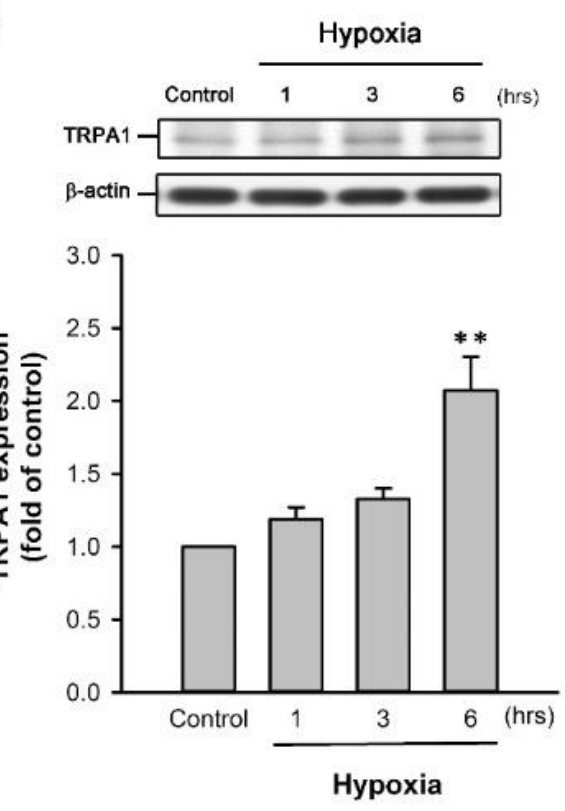

Figure 5. Increase in TRPA1 expression induced by H/R in HK-2 cells. (A) HK-2 cells were incubated under normoxia conditions as control or exposed to $2.5 \%, 5 \%$, or $10 \% \mathrm{O}_{2}$ (hypoxia) for $6 \mathrm{~h}$, followed by $4 \mathrm{~h}$ of reoxygenation. (B) HK-2 cells were incubated under normoxia conditions as control or exposed to $2.5 \% \mathrm{O}_{2}$ for 1,3 or $6 \mathrm{~h}$, followed by $4 \mathrm{~h}$ of reoxygenation. Protein expression was analyzed by Western blot. Data in each group are mean \pm SEM from 6 independent experiments. ${ }^{* *} p<0.01$ versus the control group.

\subsection{TRPA1 Mediates the Induction of IL-8 by H/R in HK-2 Cells}

The pretreatment of HK-2 cells with 3, 6, or $9 \mu \mathrm{M}$ HC-030031 (a TRPA1 antagonist) dose-dependently attenuated H/R-induced IL-8 but did not affect the basal IL-8 concentrations in cells without H/R (Figure 6A). Pretreatment with TRPA1 small interfering RNA (siRNA) for gene knockdown significantly reduced TRPA1 proteins that were available for activation (Figure 6B). Additionally, pretreatment with TRPA1 siRNA (50 nM) significantly reduced $H / R$-induced increase in IL-8 production, whereas pretreatment with scramble siRNA failed to produce such effects (Figure 6C). 


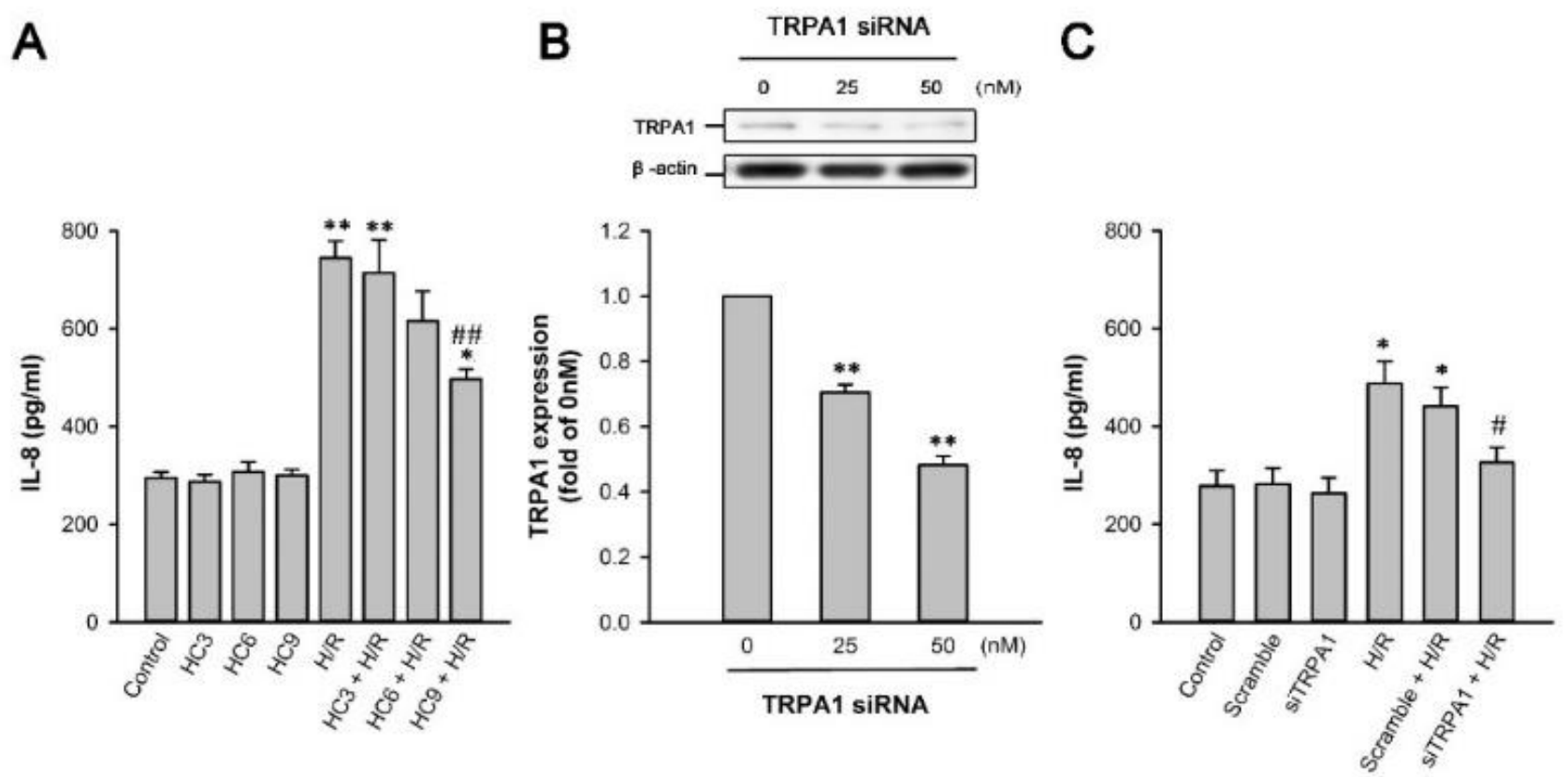

Figure 6. TRPA1 mediated the induction of IL-8 by H/R in HK-2 cells. (A) HK-2 cells were incubated under normoxia conditions as control or exposed to $2.5 \% \mathrm{O}_{2}$ for $6 \mathrm{~h}$, followed by $4 \mathrm{~h}$ of reoxygenation. In 6 study groups, cells were pretreated with 3, 6, or $9 \mu \mathrm{M}$ HC-030031 (HC3, HC6 or HC 9; a TRPA1 antagonist). (B) HK-2 cells were incubated under normoxia conditions with or without the application of TRPA1 siRNA (siTRPA1) at two concentrations (25 and $50 \mathrm{nM}$ ) $48 \mathrm{~h}$ prior to the measurement of TRPA1 expression. Protein expression was analyzed by Western blot. (C) HK-2 cells were incubated under normoxia conditions as control or exposed to $2.5 \% \mathrm{O}_{2}$ for $6 \mathrm{~h}$, followed by $4 \mathrm{~h}$ of reoxygenation. In the 4 study groups, cells were pretreated with $50 \mathrm{nM}$ of siTRPA1 or scramble siRNA. Protein expression was analyzed by ELISA. Data in each group are mean \pm SEM from 6 independent experiments. ${ }^{*} p<0.05$ versus the control group; ${ }^{* *} p<0.01$ versus the control group; ${ }^{\#} p<0.05$ versus the H/R group without pretreatment of siRNA; ${ }^{\# \#} p<0.01$ versus the H/R group without pretreatment of HC.

2.7. H/R Causes ROS-Dependent, TRPA1-Mediated Increases in Intracellular Ca2+ and NADPH Oxidase Activity in HK-2 Cells

After the exposure of $\mathrm{HK}-2$ cells to $2.5 \% \mathrm{O}_{2}$ for $6 \mathrm{~h}$, the increase in intracellular $\mathrm{Ca}^{2+}$ level peaked at $2 \mathrm{~h}$ of reoxygenation and declined at 3 and $4 \mathrm{~h}$ of reoxygenation. Nevertheless, at $3 \mathrm{~h}$, the level remained higher than the baseline level (Figure 7A). By contrast, the exposure of HK-2 cells to normoxia for the same duration did not significantly change the intracellular $\mathrm{Ca}^{2+}$ level (Figure 7B). Pretreatment with an extracellular $\mathrm{Ca}^{2+}$ chelator (EGTA), HC-030031 (a TRPA1 antagonist), or N-acetyl-cysteine (NAC, a ROS scavenger) greatly prevented $\mathrm{H} / \mathrm{R}$-induced increases in the intracellular $\mathrm{Ca}^{2+}$ level, which was measured after $2 \mathrm{~h}$ of reoxygenation but did not affect the basal intracellular $\mathrm{Ca}^{2+}$ level in cells without H/R (Figure 7B). H/R also increased NADPH oxidase activity at $2 \mathrm{~h}$ of reoxygenation (Figure 7C). Pretreatment with EGTA, HC-030031, NAC, or apocynin (an NADPH oxidase inhibitor) greatly prevented such an increase (Figure 7C). 

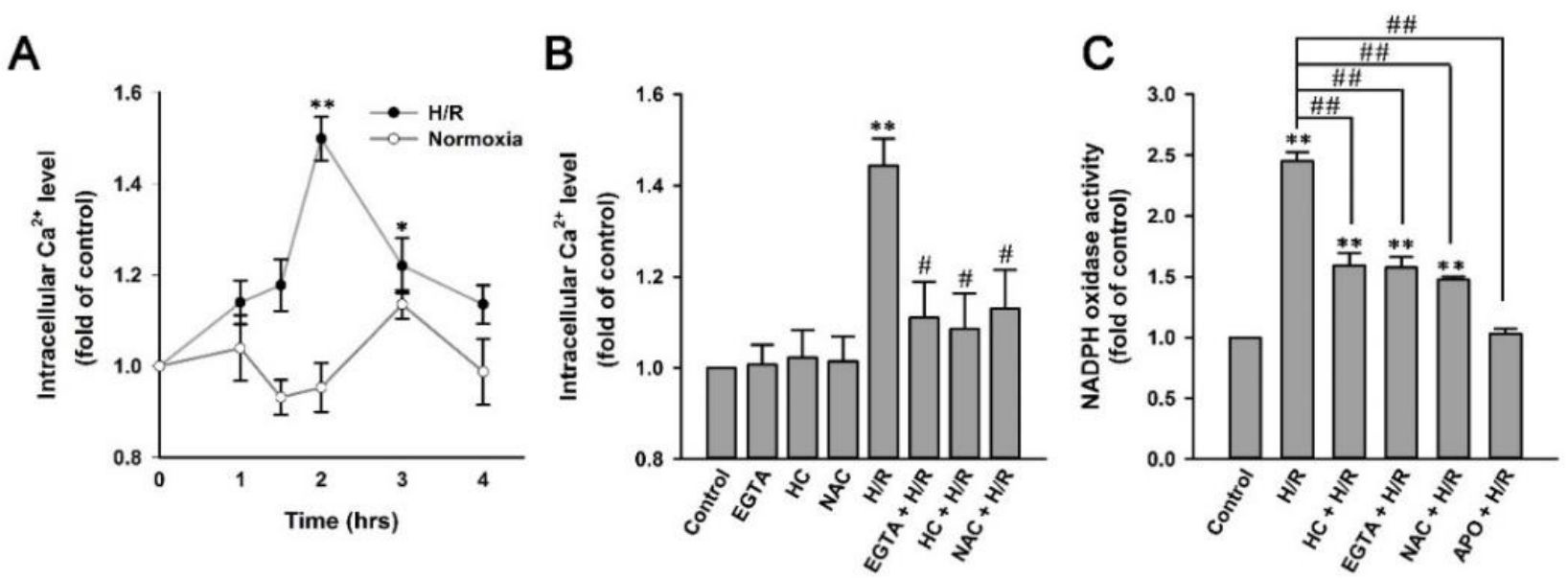

Figure 7. H/R causes ROS-dependent, TRPA1-mediated increases in intracellular $\mathrm{Ca}^{2+}$ and NADPH oxidase activity in HK-2 cells. (A) HK-2 cells were incubated under normoxia conditions or exposed to $2.5 \% \mathrm{O}_{2}$ for $6 \mathrm{~h}$, followed by 1, 1.5, 2, 3, and $4 \mathrm{~h}$ of reoxygenation. (B) $\mathrm{HK}-2$ cells were incubated under normoxia conditions as control or exposed to $2.5 \% \mathrm{O}_{2}$ for $6 \mathrm{~h}$, followed by $2 \mathrm{~h}$ of reoxygenation. In 6 study groups, cells were pretreated with EGTA (an extracellular Ca ${ }^{2+}$ chelator; $500 \mu \mathrm{M}$ ), HC-030031 (HC, a TRPA1 antagonist; $9 \mu \mathrm{M}$ ) or N-acetyl-cysteine (NAC, a scavenger of ROS; $1 \mathrm{mM}$ ). (C) HK-2 cells were incubated under normoxia conditions as control or exposed to $2.5 \% \mathrm{O}_{2}$ for $6 \mathrm{~h}$, followed by $2 \mathrm{~h}$ of reoxygenation. In 4 study groups, cells were pretreated with HC-030031, EGTA, NAC or apocynin (APO; an inhibitor of NADPH oxidase; $150 \mu \mathrm{M}$ ). Intracellular $\mathrm{Ca}^{2+}$ levels were measured by Fluo-8 fluorescent probe assay. NADPH oxidase activity was measured by $\mathrm{NADP}^{+} / \mathrm{NADPH}$ assay. Data in each group are mean $\pm \mathrm{SEM}$ from 5 independent experiments. ${ }^{* *} p<0.01$ versus the control group or time zero; ${ }^{\#} p<0.05$ versus the H/R group without drug pretreatment; ${ }^{\#} p<0.01$ versus the H/R group without drug pretreatment.

\subsection{H/R-Induced Intracellular ROS Increase via a ROS-Dependent, TRPA1-Mediated, and NOX-Released Pathway in HK-2 Cells}

After the exposure of $\mathrm{HK}-2$ cells to $2.5 \% \mathrm{O}_{2}$ for $6 \mathrm{~h}$, an increase in intracellular ROS level at $4 \mathrm{~h}$ of reoxygenation was observed (Figure 8). Pretreatment with HC-030031 (a TRPA1 antagonist; Figure 8A), an extracellular $\mathrm{Ca}^{2+}$ chelator (EGTA; Figure 8B), apocynin (an NADPH oxidase inhibitor; Figure 8C), or N-acetyl-cysteine (NAC, a ROS scavenger; Figure 8D) greatly prevented an H/R-induced increase in the intracellular ROS level after $4 \mathrm{~h}$ of reoxygenation but did not affect the basal intracellular ROS level in cells not exposed to $\mathrm{H} / \mathrm{R}$.

\subsection{MAPKs/NF-אB Pathway Is Vital for the TRPA1-Mediated Induction of IL-8 by H/R in HK-2 Cells}

Pretreatment of HK-2 cells with an inhibitor of extracellular signal-regulated kinases (ERK) (PD98059), an inhibitor of c-Jun N-terminal kinases (c-JNK) (SP600125), or an NF-kB inhibitor (BAY11-7085) significantly reduced the induction of IL-8 by H/R (Figure 9A). Moreover, compared with control cells, the exposure of HK-2 cells to H/R increased the amounts of phosphorylated ERK (Figure 9B), phosphorylated JNK (Figure 9C), and NF- $\mathrm{B}$ p65 subunit in the cell nuclei (Figure 9D). The H/R-induced activation of MAPKs/NF- $\mathrm{B}$ signaling was significantly attenuated by pretreatment with EGTA, HC-030031, or NAC (Figure 9B-D). 
A

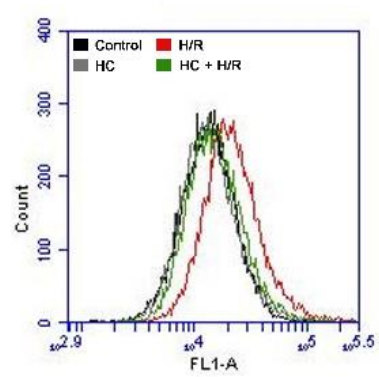

C

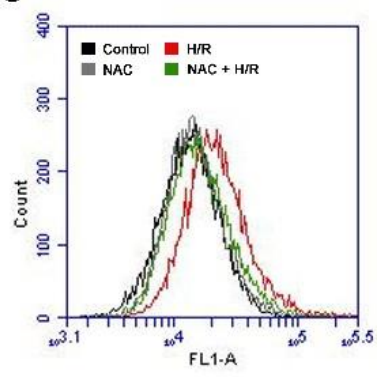

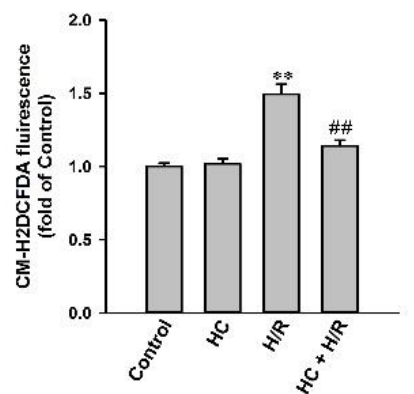

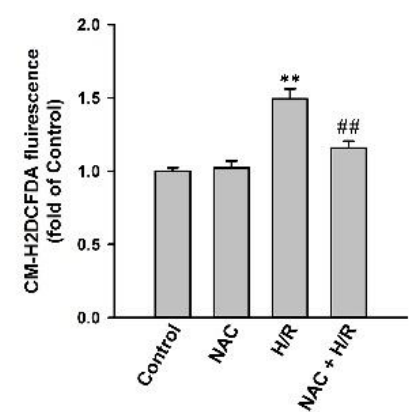

B
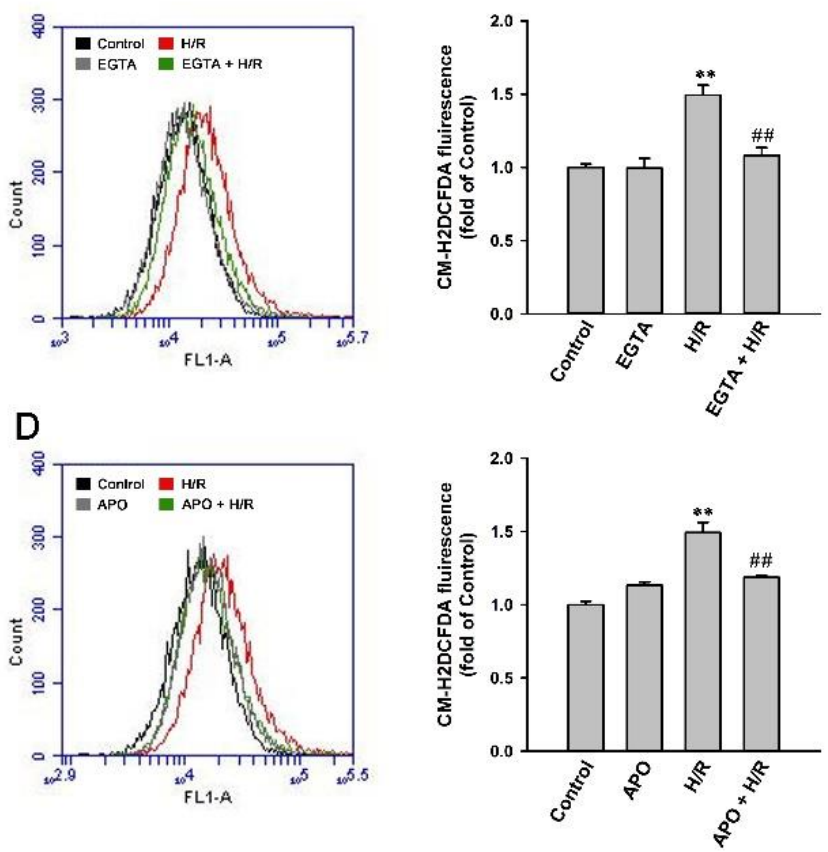

Figure 8. H/R-induced intracellular ROS increase via a ROS-dependent, TRPA1-mediated, and NOX-released pathway in HK-2 cells. (A) HK-2 cells were incubated under normoxia conditions (control) or exposed to $2.5 \% \mathrm{O}_{2}$ for $6 \mathrm{~h}$, followed by $4 \mathrm{~h}$ of reoxygenation. In two study groups, cells were pretreated with HC-030031 (HC, a TRPA1 antagonist; $9 \mu \mathrm{M}$ ). (B) HK-2 cells were incubated under normoxia conditions (control) or exposed to $2.5 \% \mathrm{O}_{2}$ for $6 \mathrm{~h}$, followed by $4 \mathrm{~h}$ of reoxygenation. In the two study groups, cells were pretreated with EGTA (an extracellular $\mathrm{Ca}^{2+}$ chelator; $500 \mu \mathrm{M}$ ). (C) HK-2 cells were incubated under normoxia conditions (control) or exposed to $2.5 \% \mathrm{O}_{2}$ for $6 \mathrm{~h}$, followed by $4 \mathrm{~h}$ of reoxygenation. In two study groups, cells were pretreated with N-acetyl-cysteine (NAC, a scavenger of ROS; $1 \mathrm{mM}$ ). (D) HK-2 cells were incubated under normoxia conditions (control) or exposed to $2.5 \% \mathrm{O}_{2}$ for $6 \mathrm{~h}$, followed by $4 \mathrm{~h}$ of reoxygenation. In two study groups, cells were pretreated with apocynin (APO; an inhibitor of NADPH oxidase; $150 \mu \mathrm{M}$ ). Intracellular ROS levels were measured by flow cytometry, and CM-H2DCFDA (general oxidative stress indicator) was used for the assay. Data in each group are the mean \pm SEM from five independent experiments. ${ }^{* *} p<0.01$ versus the control group or time zero; $\#$ \# $<0.01$ versus the $\mathrm{H} / \mathrm{R}$ group without drug pretreatment.

A

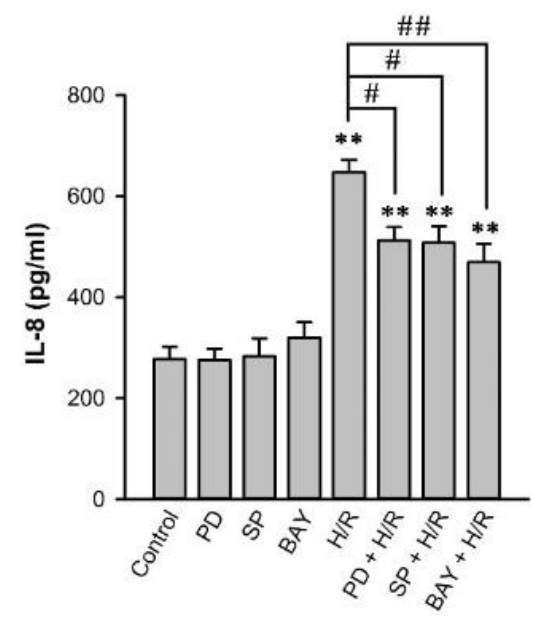

C

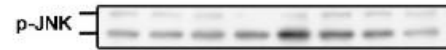

T.JNK $=-\infty-\infty-\infty-\infty-\infty$

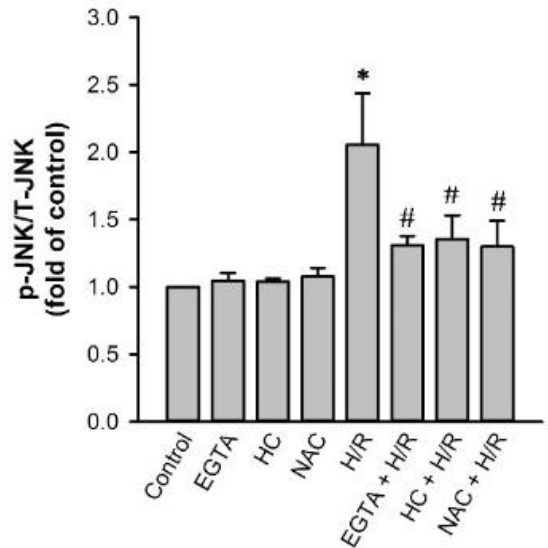

Figure 9. Cont. 
B

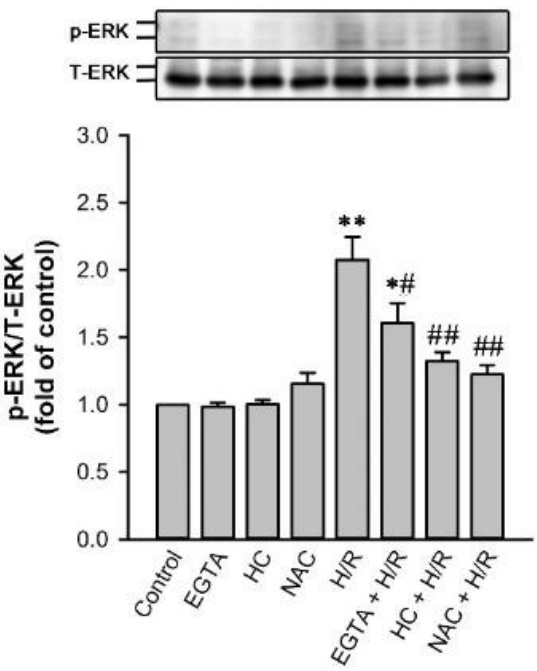

D

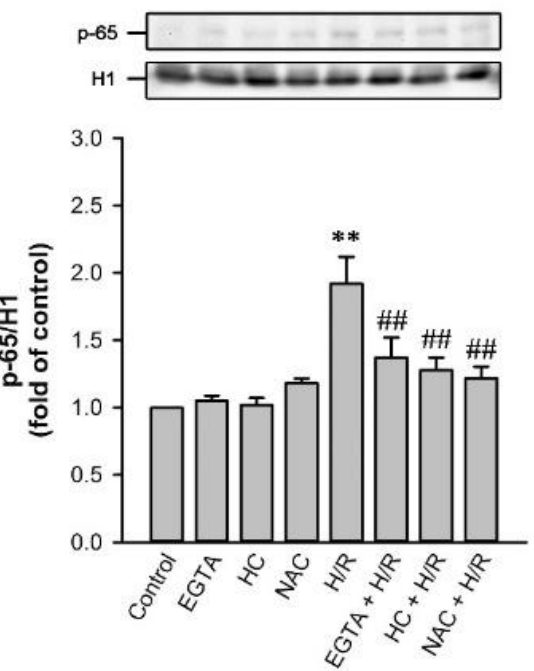

Figure 9. ERK/JNK/NF- $\kappa$ B pathway is vital for the TRPA1-mediated induction of IL- 8 by H/R in HK-2 cells. In all panels HK-2 cells were incubated under normoxia conditions as control or exposed to $2.5 \% \mathrm{O}_{2}$ for $6 \mathrm{~h}$, followed by $4 \mathrm{~h}$ of reoxygenation. (A) In 6 study groups, cells were pretreated with PD98059 (PD, an ERK inhibitor; $10 \mu \mathrm{M}$ ), SP600125 (SP, a JNK inhibitor; $10 \mu \mathrm{M}$ ) or BAY11-7085 (BAY, a NF- $\kappa$ B inhibitor; $10 \mu \mathrm{M}$ ). (B-D) In 6 study groups, cells were pretreated with EGTA, HC-030031 (HC) or N-acetyl-cysteine (NAC). Protein expression was analyzed by ELISA (A) or Western blot (B-D). Activation of ERK and JNK was indicated by increased phosphorylation of these kinases, whereas NF- $\kappa$ B activation was indicated by the increased presence of p65 subunit in the nucleus. Data in each group are as the mean \pm SEM from 5 independent experiments. ${ }^{*} p<0.05$ versus the control group; ** $p<0.01$ versus the control group; ${ }^{*} p<0.05$ versus the $\mathrm{H} / \mathrm{R}$ group without drug pretreatment; \#\# $p<0.01$ versus the $\mathrm{H} / \mathrm{R}$ group without drug pretreatment. ERK, extracellular signal-regulated kinase; JNK, c-Jun N-terminal kinase; NF- $\kappa \mathrm{B}$, nuclear factor $\kappa$-light-chain-enhancer of activated B cells; $\mathrm{H} 1$, histone protein 1 , served as the loading control for nuclear protein fractions.

\section{Discussion}

A strong correlation between the renal tubular injury and the expression of renal tubular TRPA1 or oxidative stress was demonstrated for the first time in patients with ATN and AKI (Figure 1). These observations led us to hypothesize that renal tubular TRPA1 plays a detrimental role in the pathogenesis of IR-induced AKI. We used an in vivo model with IR $[8,15,16,31]$ and an in vitro model with $\mathrm{H} / \mathrm{R}[5,30]$ to investigate the detrimental function of renal tubular TRPA1 and the underlying mechanism.

Our in vivo study results showed that, compared with the WT mice, the trpa1 ${ }^{-/-}$ mice displayed reduced levels of IR-induced inflammation and injury in the kidney. The levels were identified based on the alleviation of increased indices of oxidative stress, inflammation, dysfunction, and injury in the kidney (Figures 3 and 4). The vulnerability of renal tubular cells to oxidative stress makes their responses a key feature in the initiation of IR-induced AKI [7-9]. Therefore, we believe that the reduced renal inflammation and injury observed in our trpa1-/- mice is, at least in part, due to the absence of tubular epithelial TRPA1 functions in the trpa1 $1^{-/-}$mice. Additionally, other cell types, such as endothelial cells, macrophages, and leukocytes, may participate in the development of IR-induced AKI [13,32]. Accordingly, the lack of TRPA1 function in these cells may be related to IR-induced inflammation and injury in the kidney in trpa1 ${ }^{-/-}$mice. In addition, the correlation between macrophage movement and the function of TRPA1 channel [33-35] possibly existed in the kidney, because MCP-1 (a chemoattractant chemokine), and MIP-2 (secreted by macrophages) were reduced in trpa $^{-1-}$ mice.

Intriguingly, the IR-induced increase in the ROS level of renal tissues was lower in the trpa1 ${ }^{-/-}$mice compared with the WT mice (Figure 4). At least two sources may contribute 
to the overall level of tissue ROS. Infiltrated inflammatory cells, such as macrophages and neutrophils, are among the major sources of ROS in AKI [7,11]. Given that IR-induced renal inflammation was alleviated in $t r p a 1^{-/-}$mice, the reduced ROS level in renal tissues observed in $t r p a 1^{-/-}$mice may be due to the reduction of ROS from these sources. Renal tubular TRPA1 possibly plays inflammatory and injurious roles in the pathogenesis of IRinduced AKI, and these detrimental functions may be linked to IR-induced oxidative stress. However, Ma et al. [29] demonstrated TRPA1 may play a protective role in IR-induced AKI through inhibiting the classical activation of macrophages, especially M1 macrophages. Their results are contradictory to the present results from animal study. One explanation may be because the TRPA1 in renal tubular epithelium and macrophages might exert differential effects after IR. Eliminating the TRPA1 function in any cell leads to variable effects on IR. For the same reason, the role and mechanism of TRPA1 in myocardial IR are conflicting and remain controversial. Conklein et al. [36] stated that in mouse model of IR, the global knockout of TRPA1 results in less myocardial injury. However, Lu et al. [37] reported that the administration of the TRPA1 agonist reduced the myocardial infarct size in myocardial IR, and the activation of the TRPA1 channel during reoxygenation in vitro decreased cardiomyocyte cell death and the release of lactate dehydrogenase. Therefore, a genetically modified mouse model with cell-specific deletion of TRPA1 in kidney is needed to assess the role of TRPA1 in renal IR. Additionally, the use of different renal IR models or trpa1 ${ }^{-/-}$mice might also explain the difference in results.

Results of our in vitro study showed that the exposure of HK-2 cells to H/R caused several events. First, H/R increased IL-8 production, which can be attenuated by antagonizing TRPA1 with HC-030031 or gene silencing targeting for TRPA1 (Figure 6), suggesting the detrimental role of TRPA1 in this IL-8 induction. We consistently observed an increase in the expression of renal tubular TRPA1 in patients with AKI (Figure 1A), mice with IR (Figure 2A), and HK-2 cells with H/R (Figure 5); thus, the detrimental functions of renal tubular TRPA1 may be augmented by this increased expression. Second, H/R increased the intracellular level of $\mathrm{Ca}^{2+}$ at a time point prior to the IL-8 induction in HK-2 cells (Figure 7). This elevated intracellular level of $\mathrm{Ca}^{2+}$ clearly demonstrated the ROS-dependent activation of TRPA1 by H/R, because it could be totally prevented by EGTA, HC-030031, or NAC. TRPA1 is well known for its function in $\mathrm{Ca}^{2+}$ permeability $[19,20]$. Moreover, ROS may cause the oxidation of disulfide bonds near the pore region of these channels or produce the covalent modification of cysteines within electrophile/oxidant-sensing sites; both functions lead to the activation of TRPA1 [38,39]. NAC is membrane-permeable [40]; hence, it presumably can scavenge extracellular and intracellular ROS, both of which were possibly responsible for the activation of renal tubular TRPA1 in this study.

Third, H/R increased NADPH oxidase activity in HK-2 cells. This activity was partially suppressed by EGTA, HC-030031, or NAC and was totally abolished by apocynin (Figure 7). These findings suggest that the H/R-induced activation of NADPH oxidase was at least in part possibly due to the increase in intracellular $\mathrm{Ca}^{2+}$ after the ROS-dependent activation of TRPA1. These in vitro data suggested the vital role of NADPH oxidase in the mechanism of increased oxidative stress in IR-related AKI, as proposed by other investigators [41]. As demonstrated in our patient study, the level of renal tubular injury correlated well with the level of oxidative stress in patients with ATN and AKI (Figure 1). Thus, we speculated that the renal tissues of our patients with AKI may exhibit the overexpression of NADPH oxidase. Indeed, a clinical study reported that the expression of $\mathrm{p} 22^{\text {phox }}$ subunit of NADPH oxidase was significantly greater in patients with AKI with poor outcomes compared with those with favorable outcomes [42]. Our findings are in agreement with those of previous studies showing that the TRPA1- or stress-mediated elevation of the intracellular $\mathrm{Ca}^{2+}$ concentration acts as an upstream signal for the activation of NADPH oxidase $[26,43]$. Thus, the activation of NADPH oxidase has been known to increase the oxidative stress induced by IR in vivo [9-11] and to increase intracellular ROS induced by $\mathrm{H} / \mathrm{R}$ in vitro $[17,44]$. Additionally, a crosstalk exists between the ROS-dependent activation of TRPA1 and the TRPA1/ $\mathrm{Ca}^{2+}$-mediated production of ROS. H/R increased intracellular 
ROS level in HK-2 cells. The increase was suppressed by HC-030031, EGTA, apocynin, or NAC (Figure 8). The H/R-induced intracellular ROS probably increased via a ROSdependent, TRPA1-mediated, and NOX-released pathway in HK-2 cells. Indeed, a similar interplay is suggested in many cell types $[39,45]$. In these cells, $\mathrm{Ca}^{2+}$ signaling mediated by various $\mathrm{Ca}^{2+}$ channels can regulate NADPH oxidase activity, thereby increasing intracellular ROS, which can regulate the activity of these $\mathrm{Ca}^{2+}$ channels in a reciprocal manner [32]. This crosstalk was present in our in vitro model.

Lastly, H/R activated the MAPK/NF-kB signaling in HK-2 cells (Figure 9). Using pharmacological inhibitors, we proved that this signaling was involved in the induction of IL-8 by H/R (Figure 9A). The activation of the MAPK/NF- $\mathrm{KB}$ signaling was dependent on the functions of TRPA1, $\mathrm{Ca}^{2+}$, and ROS because it was prevented by HC-030031, EGTA, or NAC (Figure 9). Previous studies showed that the activation of this signaling pathway contributes to the pathogenesis of IR-induced AKI $[5,11,16-18]$. Intracellular $\mathrm{Ca}^{2+}[26,46]$ and $\operatorname{ROS}[5,11,17,26]$ are potential triggers for the activation of this signaling. We further characterized this pathway. It is a process that relies on the ROS-dependent activation of TRPA1. This finding provided additional evidence that increased our understanding of the cellular events involved in the transcription regulation of IL- 8 by H/R in renal tubular cells.

The present study had several limitations. First, the mouse model of unilateral renal IR with contralateral nephrectomy was chosen because of the high mortality rate of mice after bilateral renal IR in our animal experiment, even if the AKI model is more relevant to human pathological conditions. Second, the primary cultured cells from kidneys after IR cannot survive for a long time under our experimental conditions, as the cells are damaged in the oxidative challenges. Therefore, we chose HK-2, which is an immortalized proximal tubule epithelial cell line from normal adult human kidney, for the in vitro molecular study. Third, the measurement of 4-hydroxynonenal (4-HNE), an important oxidative stress maker and an agonist of TRPA1, was not performed in our in vivo and in vitro study.

Currently, TRPA1 is not the only type of TRP channels that purportedly to participates in the regulation of renal physiology and pathology. A recent review article by Ma et al. [47] summarized the evidence that TRP channel, subfamily C, and member 6 (TRPC6) expressed in several types of renal cells are involved in renal injury in animal models and human subjects. Ma et al. also showed that TRPC6 is ROS-sensitive, and its regulatory role in $\mathrm{Ca}^{2+}$ signaling is vital to oxidative stress-related kidney diseases [47]. Wu et al. [48] showed that the knockout or pharmacological inhibition of TRPC6 in mice ameliorates renal fibrosis induced by unilateral ureteral obstruction. Gao et al. [49] reported that TRP channel, subfamily M, member 2 (TRPM2) is localized mainly in the kidney proximal tubular epithelial cells of mice. Similar to our findings, the knockout or pharmacological inhibition of TRPM2 in mice attenuates IR-induced inflammation, injury, elevated oxidative stress, and increased NADPH oxidase activity in the kidney [50]. Chen et al. [51] reported that the activation of transient receptor potential vanilloid 1 (TRPV1) by agonists ameliorates IR-induced AKI in rats, but these channels are localized in the sensory nerves distributed in the kidney.

\section{Materials and methods}

\subsection{Reagents}

Antibodies, kits and reagents used are described in Supplemental Tables S1 and S2.

\subsection{Human Study}

A total of 10 adult patients with AKI and biopsy-proven ATN at Changhua Christian Hospital, Taiwan who were not kidney transplant recipients and did not have active malignancy, were recruited. They met the Acute Kidney Injury Network criteria [52], but AKI was not pre-renal or had obstructive etiology. The clinical information of the biopsyproven ATN patients is listed in Supplemental Table S3. For the control group, 10 adult patients who had normal kidney functions were enrolled; they received nephrectomy for localized circumscribed renal tumors. Normal renal tissues were obtained from the 
uninvolved poles of removed kidneys. The study was approved by the Institutional Review Board of Changhua Christian Hospital (approval number 150912; approval date Nov 14, 2015).

\subsection{Animals and Renal Ischemia-Reperfusion Injury Model}

Male trpa1 ${ }^{-/-}$mice (Jackson Laboratory, ME, USA), which had the S5/S6 transmembrane domains of the targeted gene deleted, were functional knockout mice. Male trpa1 ${ }^{-1-}$ mice and WT C57BL/ 6 mice (National Laboratory Animal Center, Taipei, Taiwan) were housed in individual cages under specific pathogen-free conditions in an air-conditioned animal facility and were exposed to a $12 \mathrm{~h} / 12 \mathrm{~h}$ light/dark cycle. The mice had free access to water and food.

The method to perform renal IR was described previously [31]. Renal IR was performed in 8-12 week-old mice 20-25 g in weight under deep anesthesia. Anesthesia treatment was conducted by using MatrxTM VIP 3000 Vaporizer with isoflurane. The right kidney was removed from each mouse after clamping the renal pedicle. After 1 week, the left kidney was exposed and a microvascular clip was used to clamp the pedicle of the left kidney for $30 \mathrm{~min}$ as renal ischemia. The clamp was removed, and the surgical wound was closed after the color of left kidney changed from purple to deep red. After $24 \mathrm{~h}$ of reperfusion, the mice were euthanized. Kidneys from age-matched and sham-operated mice served as controls.

\subsection{Cell Culture and $H / R$ Model}

HK-2 cells were cultured under standard cell culture conditions $\left(37^{\circ} \mathrm{C}, 5 \% \mathrm{CO}_{2}, 21 \%\right.$ $\mathrm{O}_{2}$, and $74 \% \mathrm{~N}_{2}$ ) in Dulbecco's modified Eagle's medium (DMEM, Corning Mediatech, Manassas, VA, USA) containing $4.5 \mathrm{~g} / \mathrm{L}$ glucose, L-glutamine, and sodium pyruvate and supplemented with $10 \%$ fetal bovine serum (FBS, Thermo Fisher Scientific, Waltham, MA, USA) and $1 \% 100 \times$ penicillin-streptomycin solution. The method used to perform $\mathrm{H} / \mathrm{R}$ was described previously $[5,29]$. For the hypoxic treatment, HK-2 cells were incubated in DMEM with $5 \%$ FBS in a hypoxic chamber containing various concentration of oxygenation for different durations. After hypoxia, the cells were maintained under standard cell culture conditions and subjected to reoxygenation for different durations $(0-4 \mathrm{~h})$. HK-2 cells cultured in DMEM under normoxic conditions were used as control.

\subsection{Histopathology and Tubular Injury Score}

Formalin-fixed and paraffin-embedded human and experimental murine kidney tissues were sectioned at $3 \mu \mathrm{m}$ thickness and stained for histological examination. The sections were stained with a periodic acid-Schiff (PAS) staining kit according to the manufacturer's instructions. Twenty randomly selected sections were assessed. Tubular injury (tubular cell swelling, loss of brush border, or nuclear condensation) was scored from 0 to 4 ( 0 , no change; 1 , changes affecting $25 \%$ of the section; 2 , changes affecting $25 \%$ to $50 \%$; 3 , changes affecting $50 \%$ to $75 \%$; and 4 , changes affecting $75 \%$ to $100 \%$ ) as previously described [6,51].

\subsection{Immunohistochemistry}

Immunohistochemistry (IHC) of human and murine renal tissues was performed with previously described methods [5]. Rabbit Ab against TRPA1 or mouse Ab against 8-OHdG was used. Immunoglobulin G (IgG) Ab was used as the negative control. An evaluation of IHC staining was performed by computer-assisted pixel counts (ImagePro Plus 6.0, Media Cybernetics, Silver Spring, MD, USA). Twenty areas from each IHC sample were randomly selected in the renal cortex and examined under a microscope, and the images were captured with an Olympus Microscope BX51 (Olympus, Tokyo, Japan). Quantitative immunohistochemical staining value was calculated as the integrated optical density divided by the total area occupied by the DAB-stained and hematoxylin-stained cells of each slide. 


\subsection{Serum BUN and Creatinine}

Before operation and at the time of euthanasia, blood samples were collected from the facial veins of the mice and placed into an Eppendorf tube to measure the serum BUN and creatinine. The measurements were performed with the reagent strips of Arkray Spotchem TMII and Spotchem EZ SP-4430 (Arkray, Minneapolis, MN, USA).

\subsection{Tissue Superoxide Production}

Superoxide counts were measured using a previously described method [5] with minor modifications. Murine renal tissue was homogenized and chemiluminescence (CL) was measured continuously with an Analyzing System (CLD-110, Tohoku Electronic Industry Co., Sendai, Japan). Total CL was calculated by integrating the area under the curve and subtracting it from the background level. The assay was performed in duplicate for each sample and normalized by using the total protein weight. Data were expressed as CL count $/ 10 \mathrm{~s} / \mu \mathrm{g}$ protein.

\subsection{Inflammatory Chemokines and NGAL}

The concentrations of pro-inflammatory chemokines, MCP-1, MIP-2, neutrophil gelatinase-associated lipocalin (NGAL) from mouse renal tissues, and IL-8 from the medium under different conditions were measured using ELISA kits (MCP-1, PeproTech, Rocky Hill, NJ, USA), (MIP-2, MyBioSource, San Deigo, CA, USA), (NGAL, Bioporto, Hellerup, Denmark), (IL-8, Koma Biotech, Seoul, South Korea) according to the manufacturer's instructions.

\subsection{Western Blot}

Cell pellets or murine renal tissue were homogenized in 80-100 $\mu \mathrm{L}$ of RIPA lysis buffer; the protein amount was measured using a BCA protein assay kit (Pierce Biochemical, Rockford, IL, USA). For the in vitro study, nuclear extracts were prepared using a previous method [53]. An equal amount of protein was separated on 10\% sodium dodecyl sulfatepolyacrylamide gel by electrophoresis (SDS-PAGE) and then transblotted onto a PVDF membrane. After being blocked with T-pro fast blocking buffer, the blots were incubated with primary Abs and then with corresponding secondary Abs. The protein bands were detected with an ECL kit and then quantified by Image J (1.50i, National Institutes of Health, Bethesda, MD, USA). In the animal study, kidney tissues from the renal IR of trpa1 ${ }^{-/-}$ and WT mice and from the sham operation of $t r p a 1^{-/-}$and WT mice were analysed by Western blot. In the in vitro study, HK-2 cells were incubated under normoxia or exposed to different $\mathrm{O}_{2}$ concentrations for $6 \mathrm{~h}$, followed by $4 \mathrm{~h}$ reoxygenation or different times of $2.5 \% \mathrm{O}_{2}$ and finally $4 \mathrm{~h}$ of reoxygenation. HK-2 cells were incubated under normoxia with or without the application of TRPA1 siRNA (siTRPA1) at two concentrations (25 and $50 \mathrm{nM}$ ) for $48 \mathrm{~h}$ prior to the measurement of TRPA1 expression. HK-2 cells pre-treated with EGTA, HC-030031 (HC) or N-acetyl-cysteine (NAC) were also incubated under normoxia or exposed to $2.5 \% \mathrm{O}_{2}$ for $6 \mathrm{~h}$, followed by $4 \mathrm{~h}$ of reoxygenation to investigate the MAPK/ NF- $\mathrm{kB}$ signalling pathway. The protein expression in these in vitro studies were analysed by Western blot. HK-2 cells were exposed to all pre-treated reagents for $1 \mathrm{~h}$ prior to hypoxia or normoxia treatment.

\subsection{1. siRNA Transfection}

HK-2 cells were seeded in 6-well plates overnight. Then, the transient transfection of scramble siRNA (non-targeting negative control) or siRNAs against human TRPA1 (ON-TARGET plus Human TRPA1 siRNA, Dharmacon, CO, USA) was performed for $48 \mathrm{~h}$ using DharmaFECT transfection reagents according to the manufacturer's instructions. TRPA1 expression was detected by Western blot analysis. In some experiments, transiently transfected cells were subjected to H/R treatment, and IL-8 expression was detected. The sequences of siRNAs against TRPA1 are listed in the Supplemental Table S4. 


\subsection{Intracellular Ca2+ Levels and NADPH Oxidase Activity}

Intracellular $\mathrm{Ca}^{2+}$ levels were determined using a Screen QuestTM Fluo-8 Medium Removal Calcium Assay Kit (AAT Bioquest, Inc., Sunnyvale, CA, USA), which is based on fluorescence intensity. The cells were cultured in growth medium overnight. Afterward, the medium was replaced by Fluo-8 NW dye-loading solution, a calcium indicator that can reflect the intracellular calcium level. Motion fluorescence intensity at $\mathrm{Ex} / \mathrm{Em}=490 / 525 \mathrm{~nm}$ was determined after $1 \mathrm{~h}$ of incubation at room temperature. NADPH oxidase activity was examined using an EnzyChromTM NADP ${ }^{+} / \mathrm{NADPH}$ assay kit (BioAssay Systems, Hayward, CA, USA), which is based on a glucose dehydrogenase cycling reaction in which the formed NADPH reduces a formazan reagent. The intensity of the reduced product colour at $565 \mathrm{~nm}$ is proportional to the $\mathrm{NADP}^{+} / \mathrm{NADPH}$ concentration and reflects the NADPH oxidase activity in the tested samples.

\subsection{Detection of ROS by Flow Cytometry}

ROS generation was measured using the CM-H2DCFDA fluorescence dye (Thermo Fisher Scientific, Waltham, MA, USA). To detect ROS, the HK-2 cells were pretreated with $9 \mu \mathrm{M}$ HC-030031, $500 \mu \mathrm{M}$ EGTA, $150 \mu \mathrm{M}$ APO, or $1 \mathrm{mM}$ NAC for $1 \mathrm{~h}$ before transferring to a hypoxic chamber containing 2.5\% oxygen for $6 \mathrm{~h}$, followed by reoxygenation for $4 \mathrm{~h}$. Subsequently, cells were washed twice with PBS, detached with Accutase (Corning Mediatech, Manassas, VA, USA), and resuspended in $1 \mathrm{~mL}$ of PBS, and $1.5 \mu \mathrm{L}$ of $0.5 \mathrm{mM}$ CM-H2DCFDA. The cells were gently mixed and incubated for $15 \mathrm{~min}$ at $37^{\circ} \mathrm{C}$ in the dark. Next, the cells were rewashed and suspended in $300 \mu \mathrm{L}$ of cold PBS. Finally, the ROS generation concentrations were monitored using a flow cytometer (Accuri C6, BD Biosciences, Mississauga, ON, Canada), and data were processed with the Accuri C6 software (BD Biosciences). The fluorescence intensity in cells was determined by integrating the area under the curve of the spectrum using flow cytometry. The average of the fluorescence intensity in HK-2 cells under normoxic conditions was used as the control.

\subsection{Statistical Analysis}

The results are shown as mean \pm standard error of the mean (SEM). Statistical analysis was performed by one-way analysis of variance followed by Dunnett's test or Fisher's least significant difference for multiple comparisons as appropriate. The association between two variables was analyzed by using Pearson's correlation. Differences were considered statistically significant at $P<0.05$.

\section{Conclusions}

In summary, results from our patient study suggested that the expression of renal tubular TRPA1 is well correlated with renal tubular injury or oxidative stress in patients with ATN and AKI. Our in vivo findings indicated that renal tubular TRPA1 plays a detrimental role in IR-induced AKI. Our in vitro findings suggested that the ROS-dependent activation of TRPA1 is responsible for the increased intracellular $\mathrm{Ca}^{2+}$, the increased NADPH oxidase activity, the activation of the MAPK/NF- $\mathrm{KB}$ signaling, and the induction of IL-8 in renal tubular cells with $\mathrm{H} / \mathrm{R}$. Thus, renal tubular TRPA1 may act as an oxidative stress sensor and a crucial regulator in the activation of signaling pathways and may promote the subsequent transcriptional regulation of IL-8. This cellular mechanism may possibly be at work in patients with AKI or mice with IR (Figure 10). Our findings provided significant novel information about the pathogenic mechanisms associated with IR-induced AKI and contributed to the development of potential therapies. 


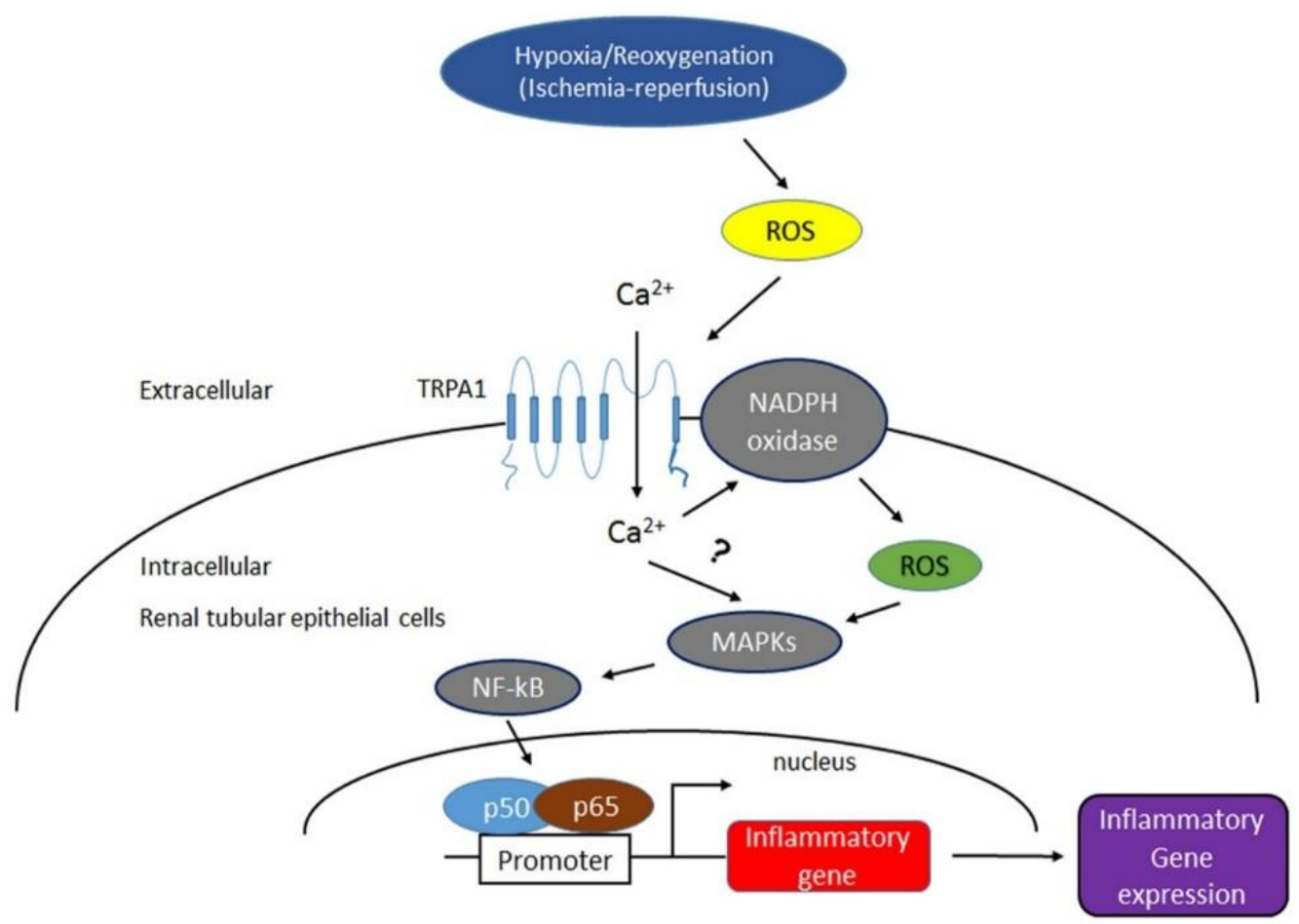

Figure 10. The proposed mechanism of TRPA1 activation in renal tubular epithelial cells by hypoxiareoxygenation $(\mathrm{H} / \mathrm{R})$ or $\mathrm{I} / \mathrm{R}$ for the induction of renal inflammation and renal injury. As shown, $\mathrm{H} / \mathrm{R}$ or I/R causes ROS increase, which in turn activates renal epithelial TRPA1, thereby, ultimately promoting of $\mathrm{Ca}^{2+}$ influx. The increase of intracellular $\mathrm{Ca}^{2+}$ in renal epithelial cells then contributes to the activation of NADPH oxidase, which can result in the elevation of the intracellular ROS. This effect activates the MAPKs/NF- $\kappa B$ signaling pathway, which allows the induction of inflammatory chemokines and aggravates renal injury.

Supplementary Materials: The following are available online at https:/ / www.mdpi.com/1422-006 $7 / 22 / 5 / 2309 /$ s1.

Author Contributions: C.-K.W., Y.R.K., and D.-C.T. designed the study; C.-K.W. and C.-L.W. carried out experiments; C.-K.W. and C.-L.W. analyzed the data; C.-K.W. and Y.R.K. made the figures; C.K.W., T.-S.L., Y.R.K., and D.-C.T. drafted and revised the paper. All authors have read and agreed to the published version of the manuscript.

Funding: This study was supported by grants SKH-8302-103-DR-006, SKH-8302-104-DR-06 from the Shin-Kong Wu Ho-Su Memorial Hospital Research Foundation, grants from the Ministry of Science and Technology, Taiwan (MOST 106-2314-B-010-039-MY3, 107-2314-B-075-064-MY3, 104-2320B-010-014-MY3, 107-2320-B-010-027-MY3, 106-2314-B-010-039-MY3, 109-2314-B-010-056-MY3 and 109-2314-B-341-003-MY3), the “Center for Intelligent Drug Systems and Smart Bio-devices (IDS2B)" from The Featured Areas Research Center Program within the framework of the Higher Education Sprout Project by the Ministry of Education (MOE) in Taiwan, and Foundation for Poison Control. The funders had no role in study design, data collection, analysis, decision to publish, or preparation of the manuscript.

Institutional Review Board Statement: The study was conducted according to the guidelines of the Declaration of Helsinki, and approved by the Institutional Review Board.

Informed Consent Statement: Informed consent was obtained from all subjects involved in the study.

Data Availability Statement: The data presented in this study are available on request from the corresponding author. The data are not publicly available due to legal restrictions imposed by the government of Taiwan in relation to the "Personal Information Protection Art". 
Acknowledgments: The authors are grateful for assistance of the KG Support-Academic Submission Services in the language editing of the manuscript. The authors thank Tzu-Cheng Su and Chung-Min Yeh from the Department of Pathology, Changhua Christian Hospital (Changhua, Taiwan) for their excellent assistance in analyzing human tissue samples.

Conflicts of Interest: No conflict of interest, financial, or otherwise are declared by the authors.

\section{References}

1. Kusch, A.; Hoff, U.; Bubalo, G.; Zhu, Y.; Fechner, M.; Schmidt-Ullrich, R.; Marko, L.; Muller, D.N.; Schmidt-Ott, K.M.; Gurgen, D.; et al. Novel signalling mechanisms and targets in renal ischaemia and reperfusion injury. Acta Physiol. 2013, 208, 25-40. [CrossRef] [PubMed]

2. Malek, M.; Nematbakhsh, M. Renal ischemia/reperfusion injury; from pathophysiology to treatment. J. Ren. Inj. Prev. 2015, 4, 20-27. [PubMed]

3. Lee, P.Y.; Chien, Y.; Chiou, G.Y.; Lin, C.H.; Chiou, C.H.; Tarng, D.C. Induced pluripotent stem cells without c-Myc attenuate acute kidney injury via downregulating the signaling of oxidative stress and inflammation in ischemia-reperfusion rats. Cell Transpl. 2012, 21, 2569-2585. [CrossRef]

4. Rovcanin, B.; Medic, B.; Kocic, G.; Cebovic, T.; Ristic, M.; Prostran, M. Molecular Dissection of Renal Ischemia-Reperfusion: Oxidative Stress and Cellular Events. Curr. Med. Chem. 2016, 23, 1965-1980. [CrossRef] [PubMed]

5. Tarng, D.C.; Tseng, W.C.; Lee, P.Y.; Chiou, S.H.; Hsieh, S.L. Induced Pluripotent Stem Cell-Derived Conditioned Medium Attenuates Acute Kidney Injury by Downregulating the Oxidative Stress-Related Pathway in Ischemia-Reperfusion Rats. Cell Transpl. 2016, 25, 517-530. [CrossRef] [PubMed]

6. Thurman, J.M. Triggers of inflammation after renal ischemia/reperfusion. Clin. Immunol. 2007, 123, 7-13. [CrossRef]

7. Basile, D.P.; Anderson, M.D.; Sutton, T.A. Pathophysiology of acute kidney injury. Compr. Physiol. 2012, 2, $1303-1353$.

8. Nezu, M.; Souma, T.; Yu, L.; Suzuki, T.; Saigusa, D.; Ito, S.; Suzuki, N.; Yamamoto, M. Transcription factor Nrf2 hyperactivation in early-phase renal ischemia-reperfusion injury prevents tubular damage progression. Kidney Int. 2017, 91, 387-401. [CrossRef] [PubMed]

9. Nie, H.; Xue, X.; Liu, G.; Guan, G.; Liu, H.; Sun, L.; Zhao, L.; Wang, X.; Chen, Z. Nitro-oleic acid ameliorates oxygen and glucose deprivation/re-oxygenation triggered oxidative stress in renal tubular cells via activation of Nrf2 and suppression of NADPH oxidase. Free Radic. Res. 2016, 50, 1200-1213. [CrossRef] [PubMed]

10. Altintas, R.; Polat, A.; Vardi, N.; Oguz, F.; Beytur, A.; Sagir, M.; Yildiz, A.; Parlakpinar, H. The protective effects of apocynin on kidney damage caused by renal ischemia/reperfusion. J. Endourol. 2013, 27, 617-624. [CrossRef]

11. Granger, D.N.; Kvietys, P.R. Reperfusion injury and reactive oxygen species: The evolution of a concept. Redox Biol. 2015, 6, 524-551. [CrossRef]

12. Bedard, K.; Krause, K.H. The NOX family of ROS-generating NADPH oxidases: Physiology and pathophysiology. Physiol. Rev. 2007, 87, 245-313. [CrossRef] [PubMed]

13. Furuichi, K.; Wada, T.; Kaneko, S.; Murphy, P.M. Roles of chemokines in renal ischemia/reperfusion injury. Front. Biosci. 2008, 13, 4021-4028. [CrossRef]

14. Wang, X.; Xiong, M.; Zeng, Y.; Sun, X.; Gong, T.; Zhang, Z. Mechanistic studies of a novel mycophenolic acid-glucosamine conjugate that attenuates renal ischemia/reperfusion injury in rat. Mol. Pharm. 2014, 11, 3503-3514. [CrossRef] [PubMed]

15. Seo, K.; Choi, J.W.; Kim, D.W.; Han, D.; Noh, S.J.; Jung, H.S. Aminophylline Effect on Renal Ischemia-Reperfusion Injury in Mice. Transpl. Proc. 2017, 49, 358-365. [CrossRef] [PubMed]

16. Xiong, C.; Zang, X.; Zhou, X.; Liu, L.; Masucci, M.V.; Tang, J.; Li, X.; Liu, N.; Bayliss, G.; Zhao, T.C.; et al. Pharmacological inhibition of Src kinase protects against acute kidney injury in a murine model of renal ischemia/reperfusion. Oncotarget 2017, 8 , 31238-31253. [CrossRef]

17. Lin, B.; Xu, J.; Feng, D.G.; Wang, F.; Wang, J.X.; Zhao, H. DUSP14 knockout accelerates cardiac ischemia reperfusion (IR) injury through activating NF-kappaB and MAPKs signaling pathways modulated by ROS generation. Biochem. Biophys. Res. Commun. 2018, 501, 24-32. [CrossRef]

18. Zhang, J.; Zhao, D.; Na, N.; Li, H.; Miao, B.; Hong, L.; Huang, Z. Renoprotective effect of erythropoietin via modulation of the STAT6/MAPK/NF-kappaB pathway in ischemia/reperfusion injury after renal transplantation. Int. J. Mol. Med. 2018, 41, 25-32.

19. Bessac, B.F.; Sivula, M.; von Hehn, C.A.; Escalera, J.; Cohn, L.; Jordt, S.E. TRPA1 is a major oxidant sensor in murine airway sensory neurons. J. Clin. Invest. 2008, 118, 1899-1910. [CrossRef] [PubMed]

20. Viana, F. TRPA1 channels: Molecular sentinels of cellular stress and tissue damage. J. Physiol. 2016, 594, 4151-4169. [CrossRef]

21. Andersson, D.A.; Gentry, C.; Moss, S.; Bevan, S. Transient receptor potential A1 is a sensory receptor for multiple products of oxidative stress. J. Neurosci. 2008, 28, 2485-2494. [CrossRef] [PubMed]

22. Dembla, S.; Hasan, N.; Becker, A.; Beck, A.; Philipp, S.E. Transient receptor potential A1 channels regulate epithelial cell barriers formed by MDCK cells. FEBS Lett. 2016, 590, 1509-1520. [CrossRef] [PubMed]

23. Kanda, Y.; Yamasaki, Y.; Sasaki-Yamaguchi, Y.; Ida-Koga, N.; Kamisuki, S.; Sugawara, F.; Nagumo, Y.; Usui, T. TRPA1-dependent reversible opening of tight junction by natural compounds with an alpha,beta-unsaturated moiety and capsaicin. Sci. Rep. 2018, 8,2251 . [CrossRef] 
24. Fernandes, E.S.; Fernandes, M.A.; Keeble, J.E. The functions of TRPA1 and TRPV1: Moving away from sensory nerves. Br. J. Pharmacol. 2012, 166, 510-521. [CrossRef]

25. Nassini, R.; Pedretti, P.; Moretto, N.; Fusi, C.; Carnini, C.; Facchinetti, F.; Viscomi, A.R.; Pisano, A.R.; Stokesberry, S.; Brunmark, C.; et al. Transient receptor potential ankyrin 1 channel localized to non-neuronal airway cells promotes non-neurogenic inflammation. PLoS ONE 2012, 7, e42454. [CrossRef] [PubMed]

26. Lin, A.H.; Liu, M.H.; Ko, H.K.; Perng, D.W.; Lee, T.S.; Kou, Y.R. Lung Epithelial TRPA1 Transduces the Extracellular ROS into Transcriptional Regulation of Lung Inflammation Induced by Cigarette Smoke: The Role of Influxed Ca(2)(+). Mediat. Inflamm. 2015, 2015, 148367. [CrossRef]

27. Zhu, J.; Zhang, S.; Geng, Y.; Song, Y. Transient receptor potential ankyrin 1 protects against sepsis-induced kidney injury by modulating mitochondrial biogenesis and mitophagy. Am. J. Transl. Res. 2018, 10, 4163-4172. [PubMed]

28. Ma, S.; Zhang, Y.; He, K.; Wang, P.; Wang, D.H. Knockout of TRPA1 exacerbates angiotensin II-induced kidney injury. Am. J. Physiol. Ren. Physiol. 2019, 317, F623-F631. [CrossRef]

29. Ma, S.; Wang, D.H. Knockout of Trpa1 exacerbates renal ischemia-reperfusion injury with classical activation of macrophages. Am. J. Hypertens. 2021, 34, 110-112. [CrossRef]

30. Conde, E.; Alegre, L.; Blanco-Sanchez, I.; Saenz-Morales, D.; Aguado-Fraile, E.; Ponte, B.; Ramos, E.; Saiz, A.; Jimenez, C.; Ordonez, A.; et al. Hypoxia inducible factor 1-alpha (HIF-1 alpha) is induced during reperfusion after renal ischemia and is critical for proximal tubule cell survival. PLOS ONE 2012, 7, e33258. [CrossRef]

31. Wei, Q.; Dong, Z. Mouse model of ischemic acute kidney injury: Technical notes and tricks. Am. J. Physiol. Ren. Physiol. 2012, 303, F1487-F1494. [CrossRef]

32. Basile, D.P.; Yoder, M.C. Renal endothelial dysfunction in acute kidney ischemia reperfusion injury. Cardiovasc. Hematol. Disord. Drug Targets. 2014, 14, 3-14. [CrossRef]

33. Trevisan, G.; Benemei, S.; Materazzi, S.; De Logu, F.; De Siena, G.; Fusi, C.; Fortes Rossato, M.; Coppi, E.; Marone, I.M.; Ferreira, J.; et al. TRPA1 mediates trigeminal neuropathic pain in mice downstream of monocytes/macrophages and oxidative stress. Brain 2016, 139, 1361-1377. [CrossRef]

34. De Logu, F.; Li Puma, S.; Landini, L.; Portelli, F.; Innocenti, A.; de Araujo, D.S.M.; Janal, M.N.; Patacchini, R.; Bunnett, N.W.; Geppetti, P.; et al. Schwann cells expressing nociceptive channel TRPA1 orchestrate ethanol-evoked neuropathic pain in mice. J. Clin. Investig. 2019, 129, 5424-5441. [CrossRef] [PubMed]

35. De Logu, F.; Nassini, R.; Materazzi, S.; Goncalves, M.C.; Nosi, D.; Degl’Innocenti, D.R.; Marone, I.M.; Ferreira, J.; Li Puma, S.; Benemei, S.; et al. Schwann cell TRPA1 mediates neuroinflammation that sustains macrophage-dependent neuropathic pain in mice. Nat. Commun. 2017, 8, 1887. [CrossRef] [PubMed]

36. Conklin, D.J.; Guo, Y.; Nystoriak, M.A.; Jagatheesan, G.; Obal, D.; Kilfoil, P.J.; Hoetker, J.D.; Guo, L.; Bolli, R.; Bhatnagar, A. TRPA1 channel contributes to myocardial ischemia-reperfusion injury. Am. J. Physiol. Heart Circ. Physiol. 2019, 316, H889. [CrossRef]

37. Lu, Y.; Piplani, H.; McAllister, S.L.; Hurt, C.M.; Gross, E.R. Transient Receptor Potential Ankyrin 1 Activation within the Cardiac Myocyte Limits Ischemia-reperfusion Injury in Rodents. Anesthesiology 2016, 125, 1171-1180. [CrossRef]

38. Takahashi, N.; Mizuno, Y.; Kozai, D.; Yamamoto, S.; Kiyonaka, S.; Shibata, T.; Uchida, K.; Mori, Y. Molecular characterization of TRPA1 channel activation by cysteine-reactive inflammatory mediators. Channels 2008, 2, 287-298. [CrossRef]

39. Song, M.Y.; Makino, A.; Yuan, J.X. Role of reactive oxygen species and redox in regulating the function of transient receptor potential channels. Antioxid. Redox Signal. 2011, 15, 1549-1565. [CrossRef]

40. Ates, B.; Abraham, L.; Ercal, N. Antioxidant and free radical scavenging properties of N-acetylcysteine amide (NACA) and comparison with N-acetylcysteine (NAC). Free Radic. Res. 2008, 42, 372-377. [CrossRef] [PubMed]

41. Karim, A.S.; Reese, S.R.; Wilson, N.A.; Jacobson, L.M.; Zhong, W.; Djamali, A. Nox2 is a mediator of ischemia reperfusion injury. Am. J. Transpl. 2015, 15, 2888-2899. [CrossRef] [PubMed]

42. Gutierrez, E.; Egido, J.; Rubio-Navarro, A.; Buendia, I.; Colio, L.M.B.; Toldos, O.; Manzarbeitia, F.; de Lorenzo, A.; Sanchez, R.; Ortiz, A.; et al. Oxidative stress, macrophage infiltration and CD163 expression are determinants of long-term renal outcome in macrohematuria-induced acute kidney injury of IgA nephropathy. Nephron. Clin. Pract. 2012, 121, c42-c53. [CrossRef] [PubMed]

43. Jiang, F.; Zhang, Y.; Dusting, G.J. NADPH oxidase-mediated redox signaling: Roles in cellular stress response, stress tolerance, and tissue repair. Pharmacol. Rev. 2011, 63, 218-242. [CrossRef]

44. Yang, Z.B.; Tan, B.; Li, T.B.; Lou, Z.; Jiang, J.L.; Zhou, Y.J.; Yang, J.; Luo, X.J.; Peng, J. Protective effect of vitexin compound B-1 against hypoxia/reoxygenation-induced injury in differentiated PC12 cells via NADPH oxidase inhibition. Naunyn Schmiedebergs Arch. Pharmacol. 2014, 387, 861-871. [CrossRef] [PubMed]

45. Hidalgo, C.; Donoso, P. Crosstalk between calcium and redox signaling: From molecular mechanisms to health implications. Antioxid. Redox Signal. 2008, 10, 1275-1312. [CrossRef]

46. Carmona, E.M.; Lamont, J.D.; Xue, A.; Wylam, M.; Limper, A.H. Pneumocystis cell wall beta-glucan stimulates calcium-dependent signaling of IL-8 secretion by human airway epithelial cells. Respir. Res. 2010, 11, 95. [CrossRef]

47. Ma, R.; Chaudhari, S.; Li, W. Canonical Transient Receptor Potential 6 Channel: A New Target of Reactive Oxygen Species in Renal Physiology and Pathology. Antioxid. Redox Signal. 2016, 25, 732-748. [CrossRef] [PubMed]

48. Wu, Y.L.; Xie, J.; An, S.W.; Oliver, N.; Barrezueta, N.X.; Lin, M.H.; Birnbaumer, L.; Huang, C.L. Inhibition of TRPC6 channels ameliorates renal fibrosis and contributes to renal protection by soluble klotho. Kidney Int. 2017, 91, 830-841. [CrossRef] [PubMed] 
49. Gao, G.; Wang, W.; Tadagavadi, R.K.; Briley, N.E.; Love, M.I.; Miller, B.A.; Reeves, W.B. TRPM2 mediates ischemic kidney injury and oxidant stress through RAC1. J. Clin. Investig. 2014, 124, 4989-5001. [CrossRef] [PubMed]

50. Yanarates, O.; Guven, A.; Sizlan, A.; Uysal, B.; Akgul, O.; Atim, A.; Ozcan, A.; Korkmaz, A.; Kurt, E. Ameliorative effects of proanthocyanidin on renal ischemia/reperfusion injury. Ren. Fail. 2008, 30, 931-938. [CrossRef]

51. Chen, L.; Marko, L.; Kassmann, M.; Zhu, Y.; Wu, K.; Gollasch, M. Role of TRPV1 channels in ischemia/reperfusion-induced acute kidney injury. PLoS ONE 2014, 9, e109842. [CrossRef]

52. Mehta, R.L.; Kellum, J.A.; Shah, S.V.; Molitoris, B.A.; Ronco, C.; Warnock, D.G.; Levin, A. Acute Kidney Injury, N., Acute Kidney Injury Network: Report of an initiative to improve outcomes in acute kidney injury. Crit. Care 2007, 11, R31. [CrossRef]

53. Beg, A.A.; Finco, T.S.; Nantermet, P.V.; Baldwin, A.S., Jr. Tumor necrosis factor and interleukin-1 lead to phosphorylation and loss of I kappa B alpha: A mechanism for NF-kappa B activation. Mol. Cell. Biol. 1993, 13, 3301-3310. [CrossRef] [PubMed] 